Article

\title{
Designing and Preparation of Fiber-Reinforced Composites with Enhanced Interface Adhesion
}

\author{
Dengxun Ren, Lin Chen, Yue Yuan, Kui Li, Mingzhen $X u$ *D and Xiaobo Liu * \\ Research Branch of Advanced Functional Materials, School of Materials and Energy, University of Electronic \\ Science and Technology of China, Chengdu 61173, China; rendenxun2008@126.com (D.R.); \\ linchen_uestc@163.com (L.C.); moonsunmars@163.com (Y.Y.); leekingue2014@163.com (K.L.) \\ * Correspondence: mzxu628@uestc.edu.cn (M.X.); liuxb@uestc.edu.cn (X.L.)
}

\begin{abstract}
The interfacial properties between fibers and resin matrices show great influence on the properties of fiber-reinforced composites. In this work, phthalonitrile containing benzoxazine (BA-ph) was chosen as the resin matrix, which combined with the glass fiber (GF) to prepare reinforced composite laminates at low temperature $\left(200^{\circ} \mathrm{C}\right)$. The poly(arylene ether nitrile) (PEN) was used to modify the GF and BA-ph matrix. Curing behaviors of the BA-ph/PEN were investigated with Differential scanning calorimetric (DSC) and Dynamic rheological analysis (DRA), and results indicated that the polymerization would be hindered by PEN due to the dilution effects. Moreover, the formation of triazine rings which assigning to the ring-forming polymerization of nitrile groups in BA-ph and PEN could improve the compatibility of BA-ph and PEN in the matrix. The SEM images of the fracture surface of the composites revealed that the brittleness of BA-ph matrix and interfacial adhesion between GFs and matrix was improved. The enhanced interfacial adhesion was detailedly discussed from the perspective of physical entanglement and the copolymerization between PEN chains on the surface of GFs and BA-ph/PEN matrix. The results of DMA also explained the toughness of BA-ph/PEN matrix, the semi-interpenetrating polymer networks and the interfacial adhesion. In sum, a feasible strategy that modifies the surface of GFs and the brittleness of the thermosetting matrix by high-performance thermoplastic polymers, which can be employed to prepare the composite laminates with improved properties.
\end{abstract}

Keywords: interfacial adhesion; surface modification; copolymerization; physical entanglement

\section{Introduction}

With the development of economy and science, the demand of high performance polymer-based composites is rapidly increased over the past years. In the areas such as automobile, electronics, new energy, and especially for the aeronautics-aerospace industry, the fiber reinforced polymer composites were widely used as the substrate and structural materials. Compared to the traditional metal materials, fiber reinforced matrix composites possess the properties such as light weight, good acid and alkali corrosion resistance, easy processing, low moisture absorption, low dielectric constant and loss, good creep resistance and thermal ability, therefore the application of high-performance matrix composites in the fields mentioned above increased and also can lower the costs, simultaneously [1-8]. Phthalonitrile resins, as one of the high-performance thermosetting resins, had drawn much attention on the researches and applications of advanced fiber-reinforced composites due to their outstanding flexural strength $(\geq 500 \mathrm{MPa})$, high thermal-oxidative stability $\left(T_{5} \% 350^{\circ} \mathrm{C}\right)$, excellent flam resistance, high Young's modulus ( $\geq 20 \mathrm{GPa}$ ) and low water absorptivity [9-12]. However, the difficulty of their polymerization has limited the wide application of the phthalonitrile-based resins and their composites. Among them, phthalonitrile containing benzoxazine (BA-ph), due to its autocatalytic 
polymerization, has been applied widely. Assigning to the active hydrogen and amine structures generated from the ring-opening polymerization of benzoxazine rings, the nitrile groups would be effectively catalyzed and ring-forming polymerization of nitrile occurred, consecutively [13]. The previous work indicated that the fiber-reinforced composites based on BA-ph exhibited satisfactory mechanical properties and excellent thermal stability $[3,12,14,15]$. However, the common defects including the weak interfacial adhesion between the matrix and the fibers, the local resin-rich inside the composites and the brittleness of the matrix, existed in the fiber-reinforced BA-ph composites. Thus, in order to obtain improved phthalonitrile-based fiber-reinforced composites, studies on the designing and preparing of fiber-reinforced matrix composites are necessary.

As is well known, the fibers bonded by matrices in the fiber-reinforced composites play the roles that carry the load and hinder the crack initiation and propagation when the composites under the load $[16,17]$. Thus, the strength of the matrices and the interfacial adhesion between fibers and matrices would mainly determine the final properties of the composites. As previously reported, the interface adhesion between fibers and the matrices could dominate the properties of the composite laminates, especially the mechanical properties [18-22]. Therefore, studies on the improvement of the interface adhesion between fibers and matrices have been carried out recent years. The glass fiber modified by titanate couplers showed outstanding interfacial adhesion with the polymer reported by Jang et al. [23]. Jing and the coauthors reported the comparison study on glass fiber modification that the glass fiber treated by silane coupling agents and graphene oxide, respectively. Results indicated that the glass fiber coated with graphene oxide significantly improved the mechanical properties and remained relatively better toughness [24]. Other researchers reported novel fiber modification method to obtain a modified fiber reinforced composites by ex-situ modification. That is, introducing a film former on the surface of the fiber before it was infused with the matrices. Results indicated that the ex-situ modification can provide improved interfacial adhesion between the glass fiber and matrix [25]. In sum, the modifications on the surface of the fibers with polymers and inorganic nanoparticles could greatly improve the properties of fiber-reinforced composites. However, for the modification with inorganic nanoparticles, the treatment should be realized under the harsh experimental conditions and the costs may be increased with complex modification operation; for the modification with polymers such as silane coupling agents, the surface modification may not meet the requirements during the processing with high temperatures. Thus, the studies on the novel modification methods of the fiber-reinforced composites are urgent need for research. In our previous work, the Poly(arylene ether nitrile) (PEN), a kind of excellent engineering thermoplastic with excellent properties, such as high glass transition temperature $\left(T_{g}>160{ }^{\circ} \mathrm{C}\right)$, good mechanical properties, high thermal stability $\left(T_{5 \%}>370{ }^{\circ} \mathrm{C}\right)[26-28]$ and good solubleness, was introduced into the phthalonitrile-based composites to obtain the improved fiber-reinforced composites [18]. Results demonstrated that the composites with the PEN decorated on the surface of the fibers possess more outstanding mechanical properties, indicating the surface modification of fibers with PEN could significantly promote the performance of composites. Moreover, with the introduction of the PEN, the mechanical properties of the composites improved in comparison with that of the pristine phthalonitrile-based composites. However, the detailed improvement mechanism of the PEN on the composites was not discussed and revealed.

In this work, the detailed effects of the PEN on the interfacial adhesion and final properties of the fiber-reinforced BA-ph composites were studied. Based on the previous results, the PEN was first applied to modify the surface of the glass fibers. Then, various contents of PEN were introduced into the BA-ph matrix to fabricate the modified fiber-reinforced composites. To further understanding the effects of PEN on the polymerization of BA-ph and the interface adhesion between fibers and BA-ph, the curing behaviors, process properties and fracture surface were investigated by differential scanning calorimetric (DSC), dynamic rheological analysis (DRA) and scanning electron microscope (SEM), respectively. Thermal-mechanical properties and the thermal stability of the composites were also studied to confirm the improved properties. 


\section{Experimental}

\subsection{Materials}

The phthalonitrile containing benzoxazine (BA-ph, yellow powder, softening point temperature $86 \pm 2{ }^{\circ} \mathrm{C}$ ) [29] and bisphenol A based Poly(arylene ether nitrile) (PEN, white powder, glass transition temperature $T_{g}=178{ }^{\circ} \mathrm{C}$ ) [26] were prepared in our laboratory. 1-Methyl-2-pyrrolidinone (NMP, purity 99\%, AR) was purchased from Kelong reagent Co., Ltd., Chengdu, China. The glass fiber (GF, EW170-100) fabric was obtained from Shenyang Gaote glass fiber Co., Shenyang, China. The PEN was washed in boiling water three times (10 min for each time) and dried in oven (Keelrein Instrument Co., Ltd., Shanghai, China) at $100{ }^{\circ} \mathrm{C}$ for $24 \mathrm{~h}$, the GF was treated at $200^{\circ} \mathrm{C}$ for $1 \mathrm{~h}$. Other materials were used without further purification.

\subsection{Preparation of PEN Modified Glass Fibers}

PEN was solved in NMP at room temperature to obtain the viscosity PEN solution. The GFs were first heat treated at $200{ }^{\circ} \mathrm{C}$ for $1 \mathrm{~h}$ and then infused with the above PEN solution. The content of PEN was controlled as $4 \mathrm{wt} \%$ according to the weight of GFs. Then, the impregnated GFs were dried in the oven at $80^{\circ} \mathrm{C}$ for $10 \mathrm{~min}, 140^{\circ} \mathrm{C}$ for $15 \mathrm{~min}$ to obtain the modified GF, labeled as $p$-GF.

\subsection{Preparation of BA-ph/PEN Blends with Various Content of PEN}

Various contents of PEN $(0,10,20,30$ and $40 \mathrm{wt} \%$, in the mass ratio of BA-ph/PEN) were mixed with BA-ph to prepare the BA-ph/PEN blends. The preparation of BA-ph/PEN blends is as follows: the BA-ph was dissolved in NMP in a three-necked flask (Shu Niu Glass Instrument Co., Ltd., Chengdu, China) equipped with a mechanical stirrer (Changzhou Rong Hua Instrument Manufacturing Co., Ltd., Changzhou, China) at $160^{\circ} \mathrm{C}$ for $2 \mathrm{~h}$, then the PEN with NMP were added into the prepared BA-ph solution at $160^{\circ} \mathrm{C}$ for $1 \mathrm{~h}$ and then the BA-ph/PEN blends were obtained.

\subsection{Preparation of $B A-p h / P E N / p-G F$ Composite Laminates}

The weight fraction of GF and matrix were designed as 60 and $40 \mathrm{wt} \%$, respectively. The $p$-GFs were impregnated with the as prepared viscosity BA-ph/PEN solution. 2 layers of the impregnated $p$-GFs were piled together and put on the flattened clean glass plate in the oven at $80^{\circ} \mathrm{C}$ for $4 \mathrm{~h}$, after that the prepregs were suspended in the oven at $160^{\circ} \mathrm{C}$ for $10 \mathrm{~min}$ to remove the solvent. Finally, the prepared prepregs were placed in a stainless mold (Chengdu Wei Da Machinery Manufacturing Co., Ltd., Chengdu, China) $(10 \mathrm{~cm} \times 10 \mathrm{~cm} \times 1.5 \mathrm{~mm})$ under the pressure of $20 \mathrm{MPa}$ via the curing procedure $180^{\circ} \mathrm{C} / 2 \mathrm{~h}$ and $200{ }^{\circ} \mathrm{C} / 2 \mathrm{~h}$. The BA-ph/PEN/p-GF composite laminates with various contents of PEN in the BA-ph matrix were prepared according to the process above presented.

\subsection{Characterizations}

Differential scanning calorimetric (DSC) analysis was applied to investigate the curing reaction of the blends though TA Instruments Modulated DSC Q100 (TA Instruments, Newcastle, DE, USA) at a heating rate of $10^{\circ} \mathrm{C} / \mathrm{min}$ under nitrogen atmosphere with the flow ratio $50 \mathrm{~mL} / \mathrm{min}$. Dynamic rheological analysis (DRA) was tested by using TA Instruments Rheometer AR-G2 (TA Instruments, Newcastle, DE, USA) with a frequency of $1 \mathrm{~Hz}$ at 160,180 and $200^{\circ} \mathrm{C}$ for different time in air atmosphere. The flexural experiments (three-point bending mode) were carried out by a SANS CMT6104 series desktop electromechanical universal testing machine (Shenzhen SANS, Shenzhen, China) at room temperature with crosshead displacement speed of $5 \mathrm{~mm} / \mathrm{min}$, and the test fixture was mounted in $10 \mathrm{kN}$ capacity. The samples $(40 \mathrm{~mm} \times 15 \mathrm{~mm} \times 1.5 \mathrm{~mm})$ were tested with a support span/sample thickness ratio of 16:1, and obtained the average value for every three samples. The morphology of the fractured surfaces of the composites was scanned though scanning electron microscope (SEM, JSM25900LV, JEOL, Akishima, Japan) operating at $20 \mathrm{kV}$. Dynamic mechanical analysis (DMA) in the 
mode of three-point bending with a frequency of $1 \mathrm{~Hz}$ was tested on a TA Instruments QDMA-800 (TA Instruments, Newcastle, DE, USA) from 50 to $350{ }^{\circ} \mathrm{C}$ at the heating rate of $5{ }^{\circ} \mathrm{C} / \mathrm{min}$ under air atmosphere. The dimension was $40 \mathrm{~mm} \times 10 \mathrm{~mm} \times 1.5 \mathrm{~mm}$, and the storage modulus and $\tan \delta$ were investigated. Thermogravimetry (TGA) was tested on a TA Instruments TGA Q50 (TA Instruments, Newcastle, DE, USA) with a heating rate of $20^{\circ} \mathrm{C} / \mathrm{min}$ under nitrogen from 50 to $800{ }^{\circ} \mathrm{C}$.

\section{Results and Discussion}

\subsection{Curing Behaviors of the BA-ph/PEN Blends}

The curing behaviors of the BA-ph and the BA-ph/PEN blends with various contents of PEN were studied by DSC and DRA. The curves are presented in Figures 1 and 2. Also, the Table 1 lists the main data of the copolymerization process. The Figure 1a corresponds to the DSC curves of the blends and Figure $1 \mathrm{~b}$ to the composites cured at $180^{\circ} \mathrm{C} / 2 \mathrm{~h}$ and $200^{\circ} \mathrm{C} / 2 \mathrm{~h}$. It can be seen from Figure $1 \mathrm{a}$ that the DSC curve of PEN exhibits a clear glass transition temperature $\left(T_{g}=178^{\circ} \mathrm{C}\right)$. The various BA-ph/PEN blends display obvious two-step curing processes, a gentle exothermic peak (marked as A) and a sharp exothermic peak (marked as B). The peak A at the temperature $226-233{ }^{\circ} \mathrm{C}$ can be assigned to the ring-opening reactions of benzoxazine rings, thus to form the Mannich bridge structures and generate the phenolic hydroxyl groups. The peak B at the temperature $268-275^{\circ} \mathrm{C}$ is related to the ring-forming polymerization of nitrile groups [30,31]. It can be seen that the initial curing temperature (at around $168^{\circ} \mathrm{C}$ ) and the temperature of two exothermic peaks slightly shift to the higher temperature with the increasing PEN content. This can be ascribed to that before the crosslinking network structure formed, the viscosity increases with the incorporation of the polymer PEN that decreases the motivation and interaction of the functional groups, thus to retard the polymerization of BA-ph/PEN to some extent [32]. What's more, the PEN molecular acts as the diluent that decreases the density of the functional groups and increases the distance between the adjacent functional groups, leading to the lower polymerization degree of the blends at the higher curing temperature [15]. Compared to the pristine BA-ph, the $\Delta H_{\text {curing1 }}$ (ring-opening reactions of benzoxazine rings) of the blends does not significantly changed, while, the $\Delta H_{\text {curing2 }}$ (ring-forming polymerization of nitrile groups) rapidly decreases as the PEN content increases ( $\geq 20 \mathrm{wt} \%$ ). From the results of the DSC, it is obvious that PEN shows few effects on the ring-opening polymerization of oxazine rings, while showing observed inhibition on the ring-forming polymerization of nitrile groups. It is well known that the nitrile groups in PEN are hard to polymerization due to its sluggishness itself, as well as the inhibition of the long molecular chains. Thus, with increasing the content of PEN, the polymerization enthalpy of nitrile groups presented in Table $1\left(\Delta H_{\text {curing } 2}\right)$ decreases. However, when the PEN content increases to $40 \mathrm{wt} \%$, the decrease trend of the polymerization enthalpy of nitrile groups weakens with increasing PEN content. It can be assigned to the fact that the nitrile groups in PEN also participated into the polymerization.

Table 1. Thermal properties of the various BA-ph/PEN blends.

\begin{tabular}{ccccccc}
\hline & $\boldsymbol{T}_{\boldsymbol{g}}\left({ }^{\circ} \mathrm{C}\right)$ & $\boldsymbol{T}_{\boldsymbol{i}}\left({ }^{\circ} \mathrm{C}\right)$ & $\boldsymbol{T}_{\text {top } 1}\left({ }^{\circ} \mathrm{C}\right)$ & $\boldsymbol{T}_{\text {top } 2}\left({ }^{\circ} \mathrm{C}\right)$ & $\Delta \boldsymbol{H}_{\text {curing1 }}(\mathrm{J} / \mathrm{g})$ & $\Delta \boldsymbol{H}_{\text {curing2 }}(\mathrm{J} / \mathrm{g})$ \\
\hline BA-ph & - & 166 & 226 & 268 & 61.22 & 60.11 \\
$10 \mathrm{wt} \%$ & - & 168 & 227 & 269 & 61.73 & 52.67 \\
$20 \mathrm{wt} \%$ & - & 168 & 230 & 270 & 69.64 & 35.32 \\
$30 \mathrm{wt} \%$ & - & 181 & 232 & 274 & 45.27 & 17.91 \\
$40 \mathrm{wt} \%$ & - & 181 & 233 & 275 & 51.02 & 13.77 \\
PEN & 178 & - & - & - & - & - \\
\hline
\end{tabular}



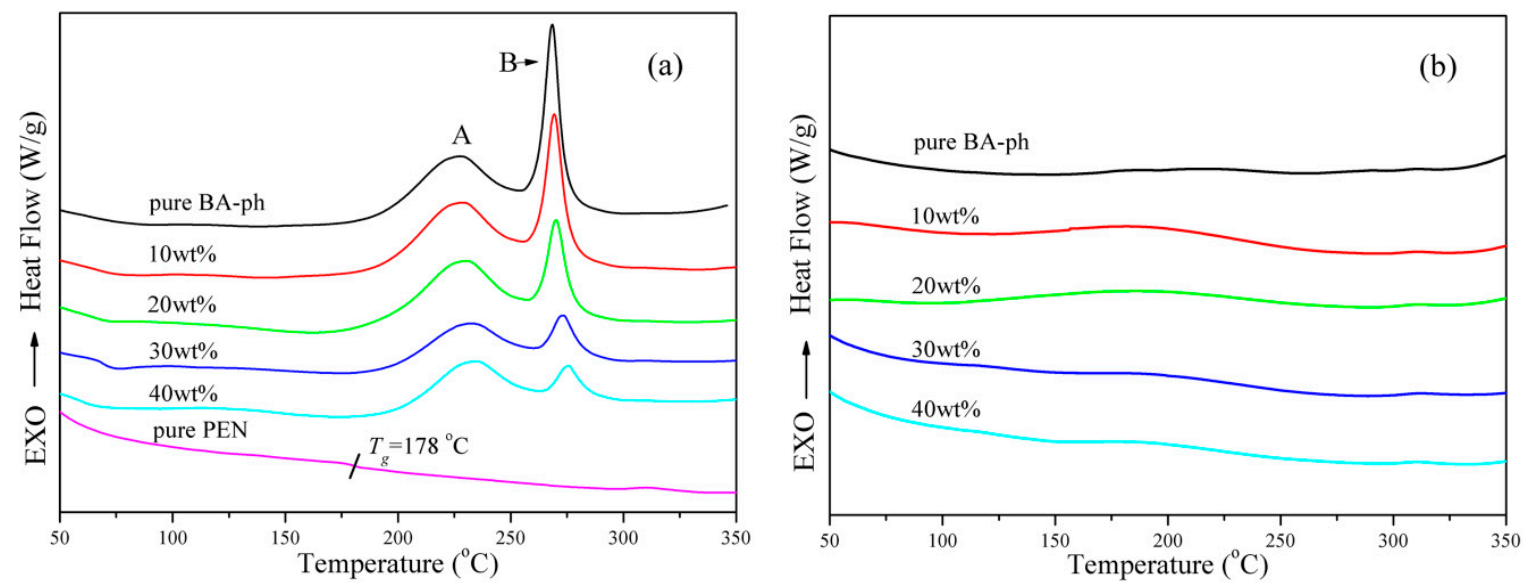

Figure 1. DSC curves of BA-ph/PEN blends, PEN and the cured BA-ph/PEN matrix: (a) BA-ph/PEN blends and pure PEN and (b) the cured matrix of the BA-ph/PEN blends.
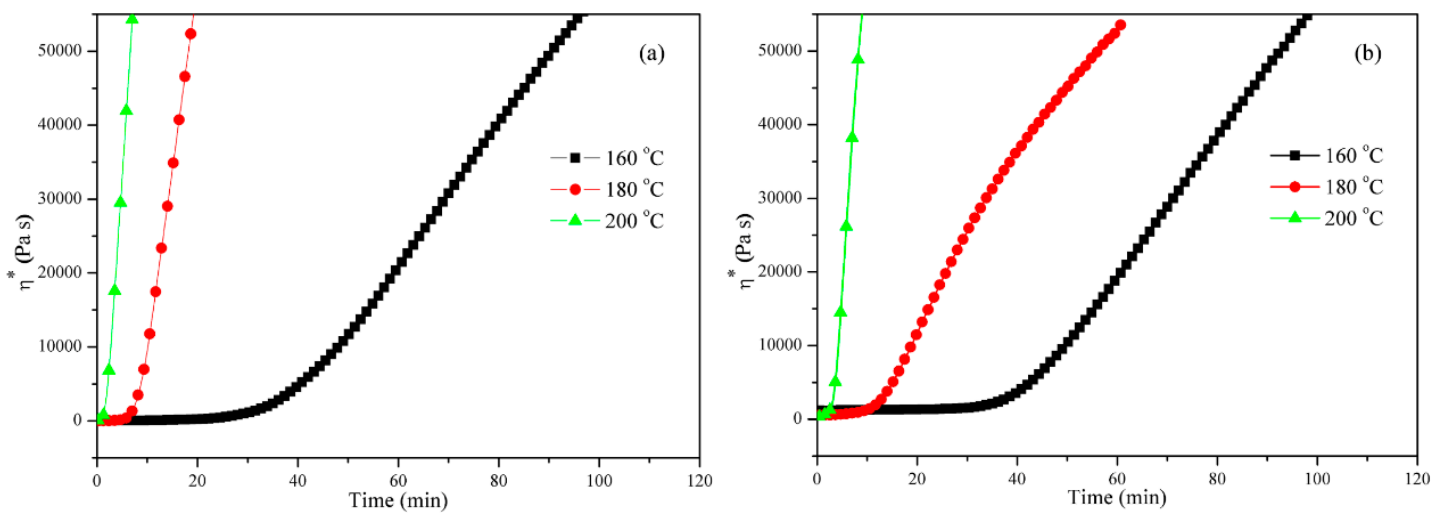

Figure 2. Viscosity of the pure BA-ph and BA-ph/PEN blends with $20 \mathrm{wt} \% \mathrm{PEN}$ content measured as a function of time at $160{ }^{\circ} \mathrm{C}, 180^{\circ} \mathrm{C}$ and $200{ }^{\circ} \mathrm{C}$ : (a) pure BA-ph and (b) BA-ph/PEN blends with 20 wt \% PEN content.

As shown in Figure 1b, the two exothermic peaks almost disappear after being treated at $180^{\circ} \mathrm{C} / 2 \mathrm{~h}$ and $200^{\circ} \mathrm{C} / 2 \mathrm{~h}$ for all of the blends. It indicates that the ring-opening polymerization of oxazine rings and the ring-forming polymerization of nitrile groups were completed at this condition. In comparison with that of previous reports, the complete polymerization of nitrile groups at $200{ }^{\circ} \mathrm{C}$ indicates the outstanding process properties of BA-ph. Moreover, due to the active hydrogen and amine structures generated from the ring-opening of oxazine, the copolymerization between PEN and BA-ph occurs in this work.

Dynamic rheological analysis was applied to study the curing behavior and processability of BA-ph and BA-ph/PEN blends. The viscosity $\left(\eta^{*}\right)$ change of BA-ph (Figure 2a) and BA-ph/PEN (Figure 2b) blends with the 20 wt \% PEN content was measured as a function of time at 160, 180 and $200{ }^{\circ} \mathrm{C}$, respectively. As shown in Figure 2, it can be seen that the viscosity of the BA-ph and BA-ph/PEN blends increased with increasing the temperature. The viscosity is stable and low before the curing reaction starts. The viscosity of the two systems is greatly influenced by the high temperature, because of that the higher temperature the faster the curing reaction occurs. It is obvious that it takes about 25,5 and $1 \mathrm{~min}$ until the reactions occur at 160,180 and $200{ }^{\circ} \mathrm{C}$, respectively. In Figure $2 b$, it takes about 32,9 and 2 min until the reaction occurs at the same temperatures, indicating that with the introduction of PEN, the polymerization rate of the matrix decreases, which is in well agreement with the results of DSC. Before the curing reaction intensively carried out, the viscosity of the BA-ph and BA-ph/PEN matrix were lower than $100 \mathrm{~Pa} \cdot \mathrm{s}$ which exhibited a good flowability. The good flowability of matrix is crucial for the preparation of the composites in the operation. The good flowability of the matrix can contribute to the good interlaminar adhesion and the smooth surface of the 
composites. Additionally, a proper operation time (about 5-10 $\mathrm{min}$ ) should be needed in the operation. So, the temperature $180^{\circ} \mathrm{C}$ was chosen as the initial processing temperature. As for the temperature $200{ }^{\circ} \mathrm{C}$, the polymerization of the matrix carried out intensively in a short time $(<1 \mathrm{~min})$ and the viscosity rapidly increased in a relatively short time. And there was no time left for the operation. Thus, considering of the processability, $180{ }^{\circ} \mathrm{C}$ can be selected as the proper process temperature. The possible curing processes of BA-ph/PEN were presented in Scheme 1.
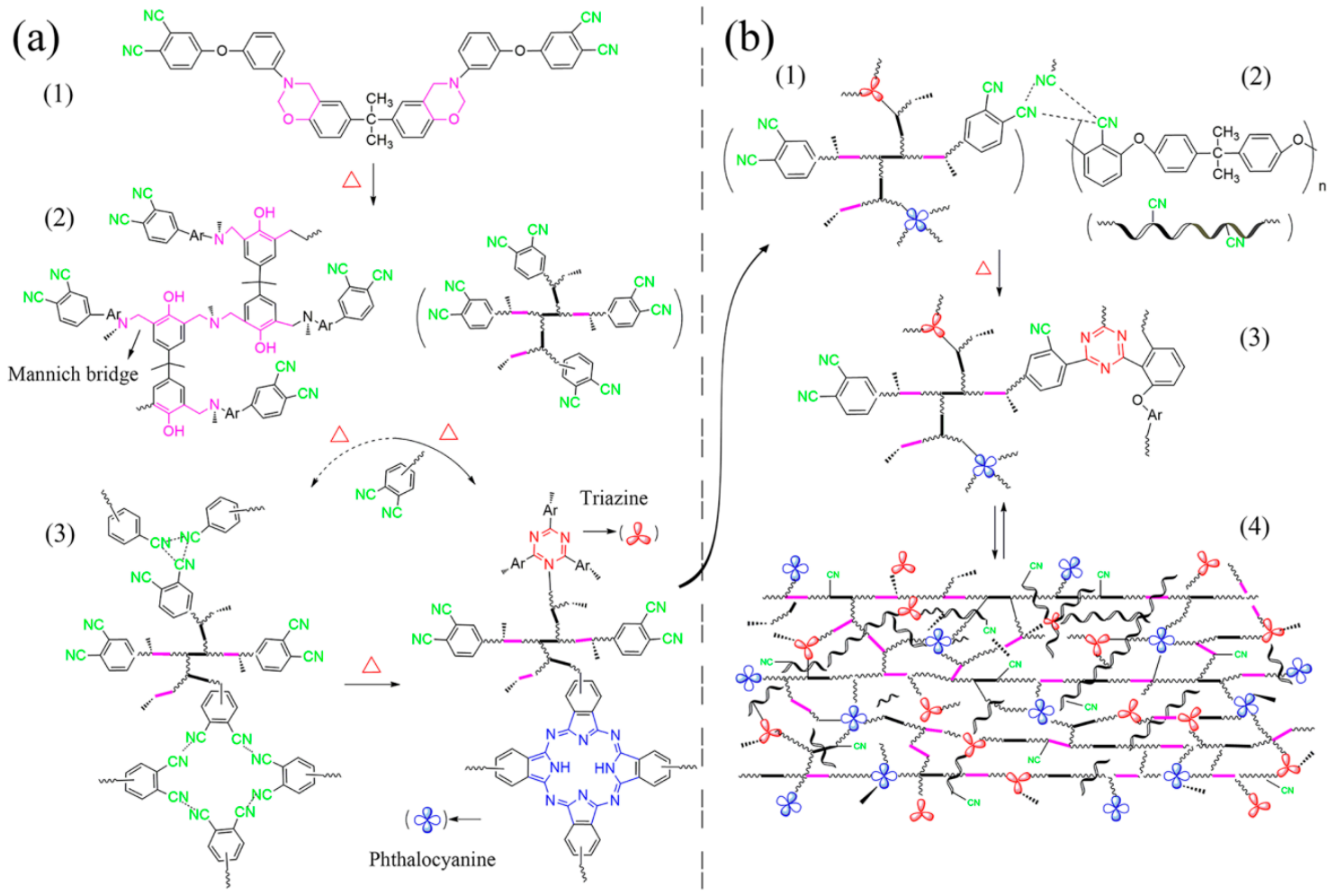

Scheme 1. (a): (1) the structure of the BA-ph, (2) the structure of Mannich bridge formed from the ring-opening of benzoxazine rings, (3) the structure of phthalocyanine and triazine rings generated from the ring-forming polymerization of the nitrile groups; (b): (1) the simplified structure of cured BA-ph, (2) the structure of PEN, (3) the structure of triazine ring derived from the copolymerization of nitrile groups between BA-ph/PEN matrix and EPN, (4) the possible structure of the matrix resins.

\subsection{Mechanical Properties of the p-GF-Reinforced Composites}

According to the results of the curing behaviors and process properties, the fiber-reinforced BA-ph/PEN composite laminates have been successfully fabricated. Mechanical properties were investigated to furthermore confirm the effects of modification of the GFs. The effects of PEN introduced into the BA-ph matrix on the flexural strength and modulus of the composites were also studied and shown in Figure 3. As shown in Figure 3a, the flexural strength of composites with various contents of PEN $(0,10,20,30,40 \mathrm{wt} \%$ ) is 391.45, 431.87 (increased by 10.3\%), 488.67 (increased by $24.8 \%$ ), 482.07 (increased by $23.1 \%$ ) and 517.22 (increased by $32.1 \%$ ) MPa, respectively. With increasing the content of PEN, the flexural strength increases correspondingly. It is well known, the flexural strength of the laminates is dominated by the matrix and the interfacial adhesion between the matrix and fibers. In this work, on the one hand, the improvement can be attributed to the flexible PEN molecular chains that can greatly increase the toughness of the BA-ph matrix [33]; on the other hand, the PEN chains decorated on the surface of the GFs also can roughen the surface, which would contribute to improve the interface interaction between fibers and the matrix. 

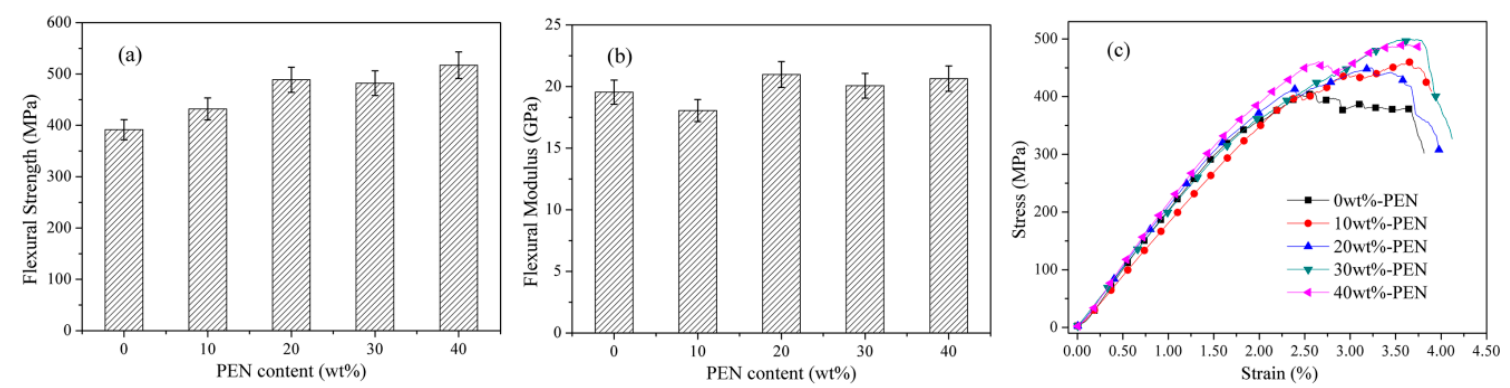

Figure 3. Mechanical properties of the various composite laminates: (a) the flexural strength, (b) the flexural modulus and (c) stress and strain curves.

Figure $3 \mathrm{~b}$ presented the flexural modulus of the composite laminates with various content of PEN in the matrix. The flexural modulus value of 19.53, 18.05 (decreased by 7.5\%), 20.97 (increased by $7.3 \%$ ), 20.06 (increased by $2.7 \%$ ) and 20.63 (increased by 5.6\%) GPa is assigning to $0,10,20,30$ and $40 \mathrm{wt} \%$ of PEN content. It is clearly that the flexural modulus decreases while the composites with $10 \mathrm{wt} \%$ PEN, then increases with increasing the content of PEN. When the PEN content reaches to $20 \mathrm{wt} \%$, the flexural modulus reaches to the maximum. The decreasing of the modulus can be explained with the fact that the thermoplastic polymer PEN acts as the plasticizer which will reduce the interaction between the rigid crosslinking networks. Then, the flexural modulus increases with the PEN content increased, this is due to the copolymerization of BA-ph and PEN that forms the semi-interpenetrating polymer networks [34]. In the discussion of DSC and DRA, the results also indicate that the copolymerization occurred between BA-ph and PEN when the content of PEN over to $20 \mathrm{wt} \%$. Considering of the modulus of the PEN and BA-ph polymers themselves, the thermosetting PEN shows a relative low modulus. Thus, persistently increasing the content of PEN (40 wt \%), the flexural modulus of the composites will present a weak increase, due to the fact that the flexible PEN chains may dominate the flexural modulus. Besides, the composite with $20 \mathrm{wt} \%$ PEN shows the highest flexural modulus, which is also ascribed to the surface modification. The better interfacial interaction would contribute to the higher mechanical properties $[18,24]$. The GFs coated with PEN increased the wettability between the GFs and the matrix. What's more, the copolymerization between the PEN and the BA-ph/PEN matrix resin occurs on the surface of GFs. In addition, the stress and strain curves were presented in Figure 3c. In sum, the modification of GFs and the BA-ph matrix with PEN simultaneously, can obviously improve the mechanical properties, including the flexural strength and modulus.

\subsection{Fracture Morphology of the p-GF-Reinforced Composites}

To further study the interface interaction and interfacial compatibility, SEM images of the fracture surface of the composites were investigated and shown in Figure 4. Figure $4 a, b, d$ presented the surface of the composites with 0, 20 and $40 \mathrm{wt} \%$ PEN. Figure $4 \mathrm{c}$ was the zoom in image of $\mathrm{b}$. It can be seen in Figure 4a that fish-scale can be obviously observed on the surface of the GFs. The fish-scale is attributed to the intertwining and accumulation of PEN chains. Although the decorated GFs possess a rough surface, the obvious cracks between the GFs and the BA-ph matrix is observed. It indicates the interfacial compatibility of the BA-ph matrix and the decorated surface is not improved intrinsically. The fracture morphology of the BA-ph matrix resin is smooth and the matrix debris exists in the gap without any adhesion to the GFs, revealing that the BA-ph matrix showed the brittleness properties.

Figure $4 \mathrm{~b}$ shows the fracture surface of the composites with $20 \mathrm{wt} \%$ PEN in the BA-ph matrix. No fish-scale can be observed on the surface of the GFs and no cracks are observed in sight, indicating the improved interfacial compatibility between the fibers and the matrix. Moreover, the GFs are coated with the BA-ph/PEN matrix, showing an obvious interface layer. The adhesion effects of the BA-ph/PEN matrix are also observed between the fibers. Figure 4c presents the zoom in image of Figure $4 \mathrm{~b}$. It can be seen that the coated matrix on the surface of the fibers and the adhesion effects of 
the BA-ph/PEN matrix are significant. As for the BA-ph/PEN matrix with $20 \mathrm{wt} \% \mathrm{PEN}$, the fracture surface is rough and irregular, which means that the toughness of BA-ph is improved by incorporation of PEN. Figure $4 \mathrm{~d}$ presents the fracture surface of the composites with $40 \mathrm{wt} \% \mathrm{PEN}$, the image exhibits good interfacial adhesion between the GF and matrix. No pulled out GFs are observed and the GFs are all embedded in the BA-ph/PEN matrix, which indicating that the interfacial compatibility of the GFs and matrix is improved. In sum, the GFs modified with PEN before being infused the prepolymers to prepared the composite laminates could significantly roughen the surface, thus to improve the interface properties of the composites.
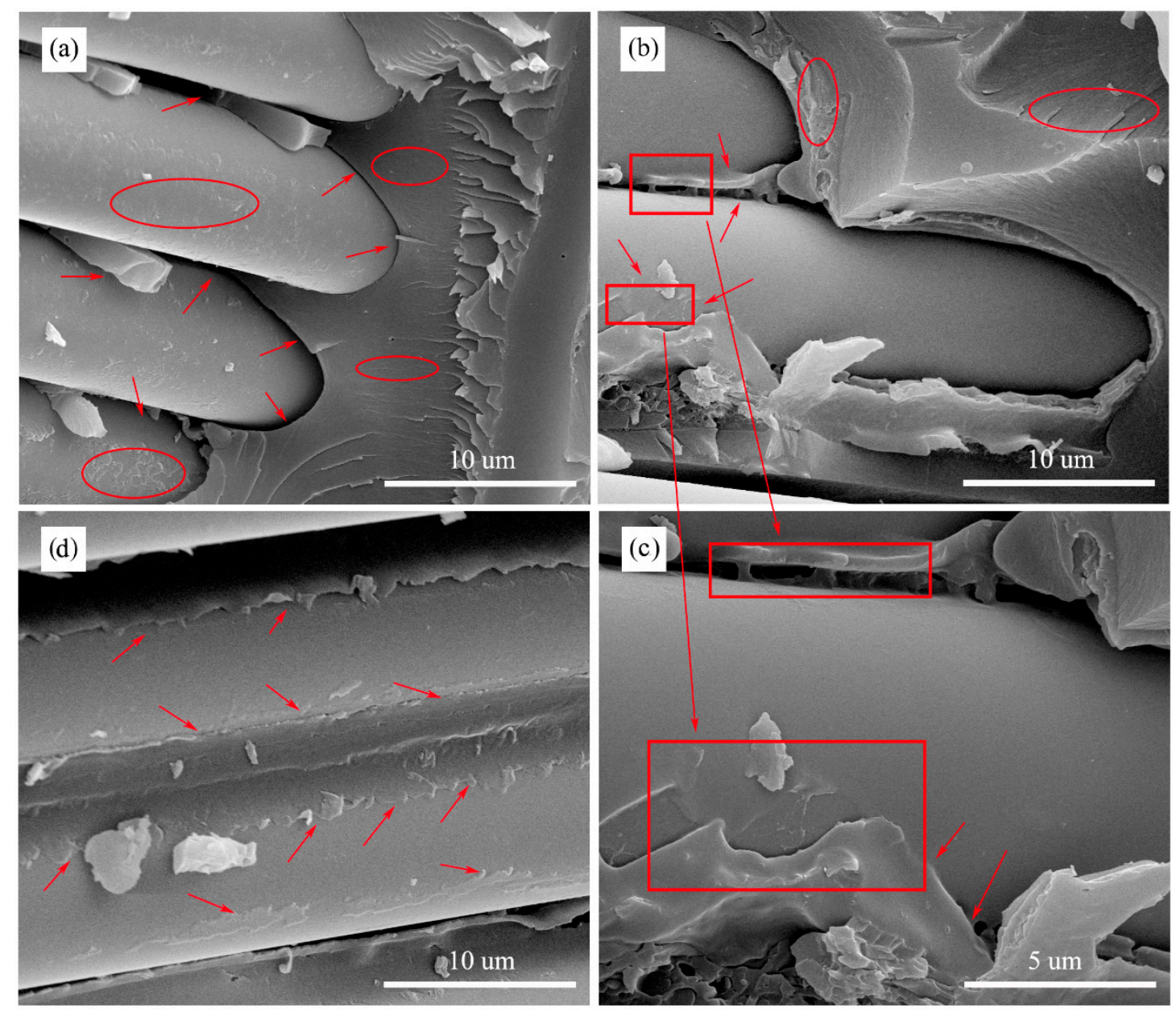

Figure 4. SEM image of the various composite laminates: (a) BA-ph; (b) BA-ph/PEN blends with 20 wt \% PEN content; (c) the zoom in image of (b,d) BA-ph/PEN blends with 40 wt \% PEN content; the arrows reflected the gaps between the matrix and GF in Figure $3 a$, as well as adhesion properties in Figure 3b-d; the ovals reflected the rough surface of GF and the smooth surface of the matrix; the rectangles marked the zoom in image of the adhesion properties of the composites in a particular area.

Moreover, the interfacial adhesion displays an obvious difference between the matrix resin with existence or not of PEN. The matrix with PEN shows better interfacial adhesion than the pristine BA-ph $/ p$-GF composite. This can be attributed to the possible facts as follows: (1) the entanglement of the long molecular chains between the PEN on the surface of GFs and in the matrix; (2) the copolymerization of nitrile groups that from PEN on the surface of GFs and from the matrix. For the BA-ph/p-GF composites, due to the high rigidity and brittleness of the thermosetting BA-ph, the entanglement between the molecular chains is difficult. What's more, the copolymerization between the BA-ph and PEN is difficult to occur due to the self-polymerization of BA-ph. Besides, the brittle 
interface layers forms mainly from the polymerization of BA-ph, will be easily destroyed under the pressure. For the matrix with PEN, BA-ph/PEN matrix possesses good compatibility with GFs due to the possible copolymerization mentioned above, as well as the physical entanglement between BA-ph/PEN blends and the PEN on the surface of GFs. Moreover, the toughness of the matrix is improved with the introduction of PEN. It's beneficial to absorb more energy and hinder the crack generation to some extent. In other words, the properties can be improved though modifying the GFs with a high performance thermoplastic polymer and then incorporating the thermoplastic polymer into the thermosetting matrix, simultaneously. The possible enhanced mechanisms of the improved interface compatibility between the decorated GFs and the BA-ph/PEN matrix are presented in Scheme 2 .

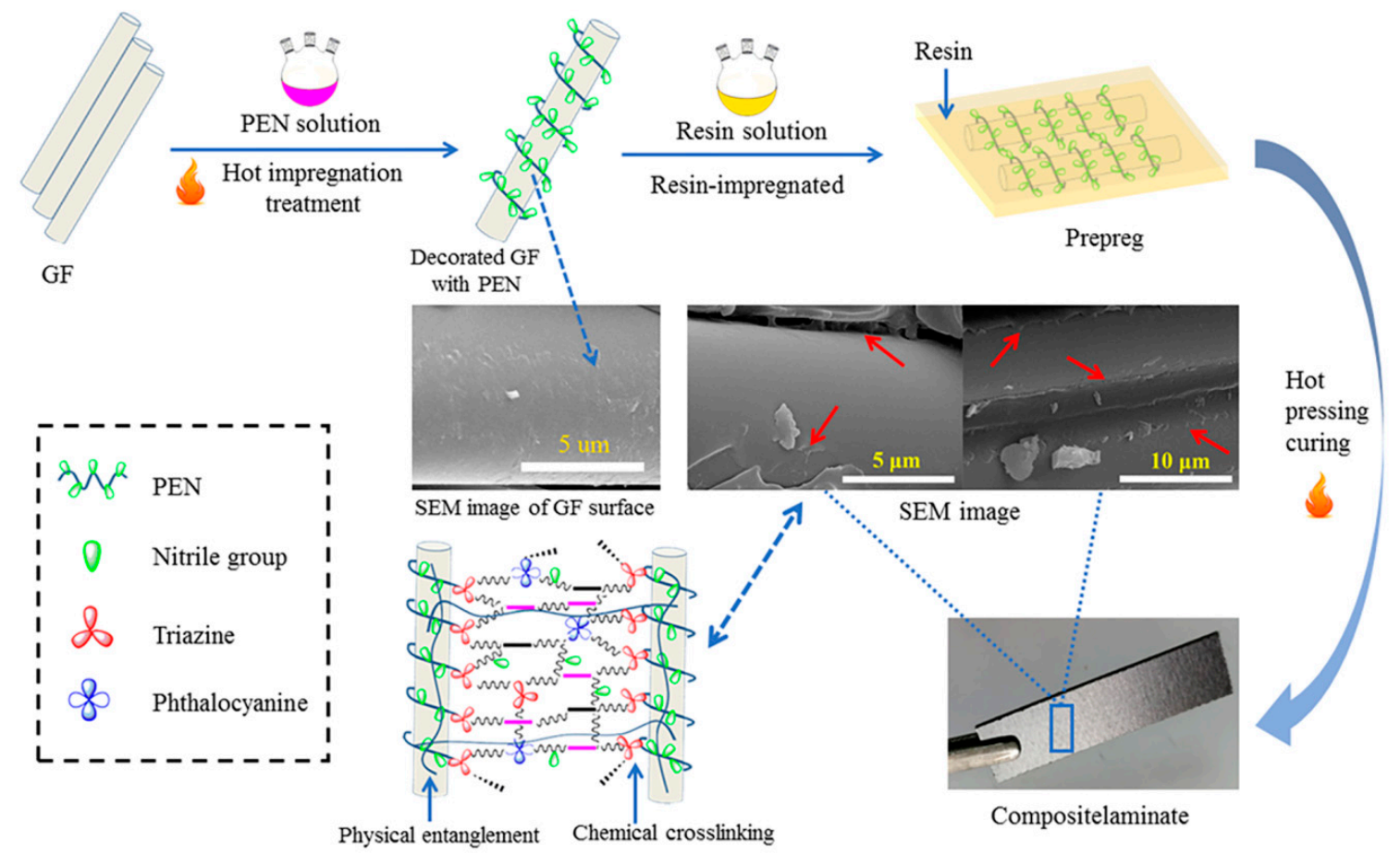

Scheme 2. The possible mechanism of the improved interfacial adhesion of the composite laminates.

\subsection{Dynamic Thermomechanical Analysis of the p-GF-Reinforced Composites}

Dynamic mechanical studies were applied to study the storage modulus and the loss tangent of the composites. Figure 5 a presented the storage modulus of the various composites as a function of temperature in range $50-350{ }^{\circ} \mathrm{C}$. It indicates that the BA-ph/PEN matrix possesses the similar rigidity. As can be seen the initial storage modulus of the composites at $50{ }^{\circ} \mathrm{C}$ increased with the incorporation of PEN, which was well in coincidence with the change of flexural modulus. So, at the lower temperature the mechanical properties of the composites were improved by adopting PEN. With increasing the content of PEN, the rigidity of the matrix decreases slightly, due to the flexible PEN chains. With increasing the test temperature, the storage modulus of the composites with PEN slightly decreases at about 150 to $210{ }^{\circ} \mathrm{C}$ and then sharply decreases at $225^{\circ} \mathrm{C}$. A platform can be observed for all of the composites at above $225^{\circ} \mathrm{C}$. It can be explained by the fact that the flexible PEN chains contribute to the decreasing of the rigidity of the matrix. When the temperature went on, the rigidity of the composites decreased faster than the composites without the PEN. As for the BA-ph/ $p$-GF composite, the storage modulus decreases rapidly after $200{ }^{\circ} \mathrm{C}$ and reaches the minimum after $280{ }^{\circ} \mathrm{C}$. This can be attributed to the fact that the BA-ph can form the rigid Mannich bridge structures and heteroaromatic rings including the phthalocyanine and triazine rings, thus to exhibit an outstanding properties at high temperatures. For the BA-ph/PEN/ $p$-GF composites, the fact that the PEN acts as plasticizer in the matrix and the movements of the PEN molecular chains at glass 
transition temperature $\left(T_{g}=178{ }^{\circ} \mathrm{C}\right.$, tested by DSC shown in Figure 1) will cause the storage modulus decrease earlier than that of the pristine BA-ph/p-GF composites.
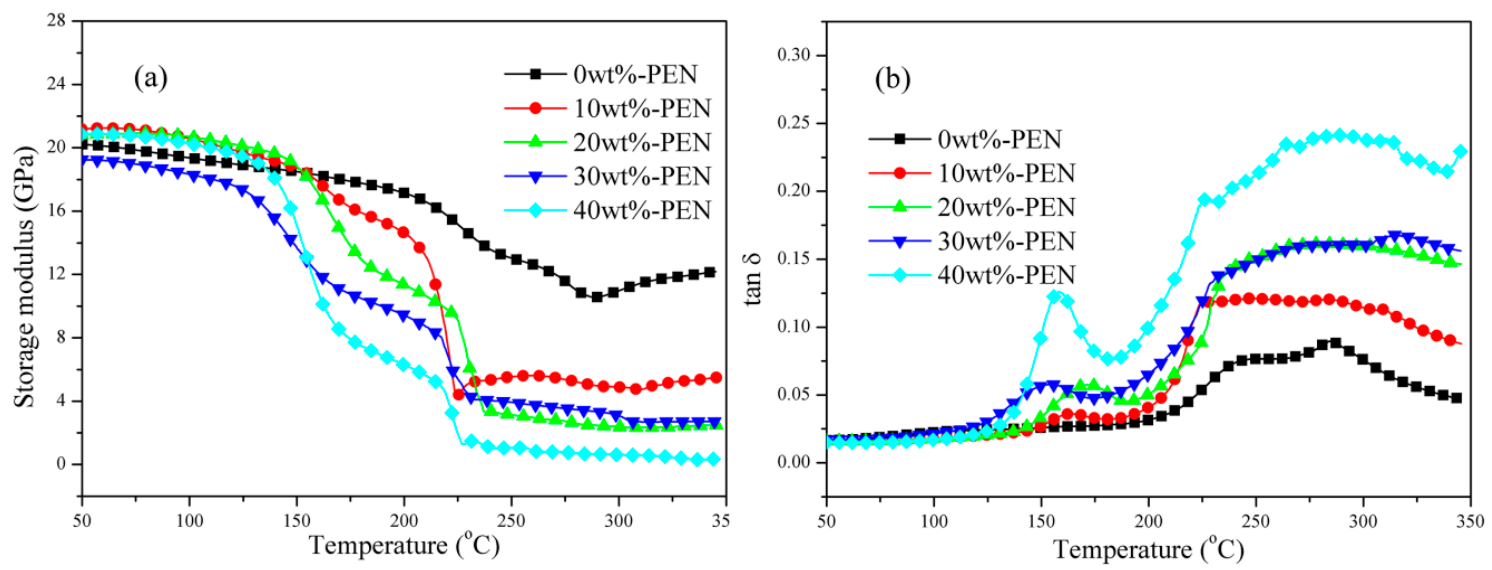

Figure 5. Dynamic mechanical analysis curves of the various composite laminates: (a) storage modulus and (b) $\tan \delta$.

The plots of $\tan \delta$ of the $p$-GF-reinforced composites were presented in Figure 5b. For the fiber-reinforced matrix composites, the $\tan \delta$ can reflect the mechanical damping effects of the composites. It is reported that the loss transitions appeared at $100-150{ }^{\circ} \mathrm{C}$ are assigned to the secondary relaxation of the molecular chains [35,36]. Then, the wide and high loss bands for all of the composites appear and could be attributed to the glass transition process. Two transitions at 225 and $280{ }^{\circ} \mathrm{C}$ are observed. The transitions can be assigned to the Mannich bridge structures and the heteroaromatic structure generated from the ring-forming polymerization of the nitrile groups. Moreover, the obvious transition processes also can be attributed to the semi-interpenetrating networks formed by the PEN chains embedded into the BA-ph polymers. With increasing the content of PEN, the height of the loss factors increased. This is due to that with the incorporation of the PEN, the rigidity of the crosslinking network decreases and the movement of molecular chains of the matrix resins increase. As we all know, the matrix resins with more flexibility will lead to more energy dissipate, that possess greater damping $[18,37]$. In sum, the introduction of PEN in the BA-ph matrix can improve the interfacial compatibility of the BA-ph/PEN/ $p$-GF composites, meanwhile, increasing the damping of the composites, that would enable them to be applied as the seismic materials with outstanding modulus and thermal-mechanical properties.

\subsection{Thermal Properties of the p-GF-Reinforced Composites}

Thermal properties of the BA-ph/p-GF and BA-ph/PEN/ $p$-GF composites were studied by TGA under nitrogen atmosphere with the heating rate of $20^{\circ} \mathrm{C} / \mathrm{min}$ from 50 to $800^{\circ} \mathrm{C}$. The curves were shown in Figure 6 and the main data was listed in Table 2, including the weight loss of $5 \mathrm{wt} \%\left(T_{5 \%}\right)$, $10 \mathrm{wt} \%\left(\mathrm{~T}_{10 \%}\right)$ and the char yield at $800{ }^{\circ} \mathrm{C}$. The thermal stability of the composites can be evaluated by the $T_{5 \%}$. As for PEN, the $T_{5 \%}$ is about $490{ }^{\circ} \mathrm{C}$, exhibiting outstanding thermal stability [26]. From the curves of TGA and the data listed in Table 2, the decomposition temperatures of $T_{5 \%}$ and the char yield for the composite laminates with $10 \%$ and $20 \%$ PEN gradually decrease with increasing the content of PEN. This is due to the fact that the PEN could hinder the polymerization of the BA-ph. The results well agree with the results of DSC testing and dynamic rheological analysis. As for the $30 \mathrm{wt} \%$ and $40 \mathrm{wt} \%$ PEN content, because of the relative high PEN content, a rapid decomposition happens at $500-550{ }^{\circ} \mathrm{C}$ which can be corresponded to the low crosslinking degree of the matrix resin with high content of PEN. In sum, the composites prepared under the current curing procedure $\left(200^{\circ} \mathrm{C}\right)$ could exhibit good thermal stability. 


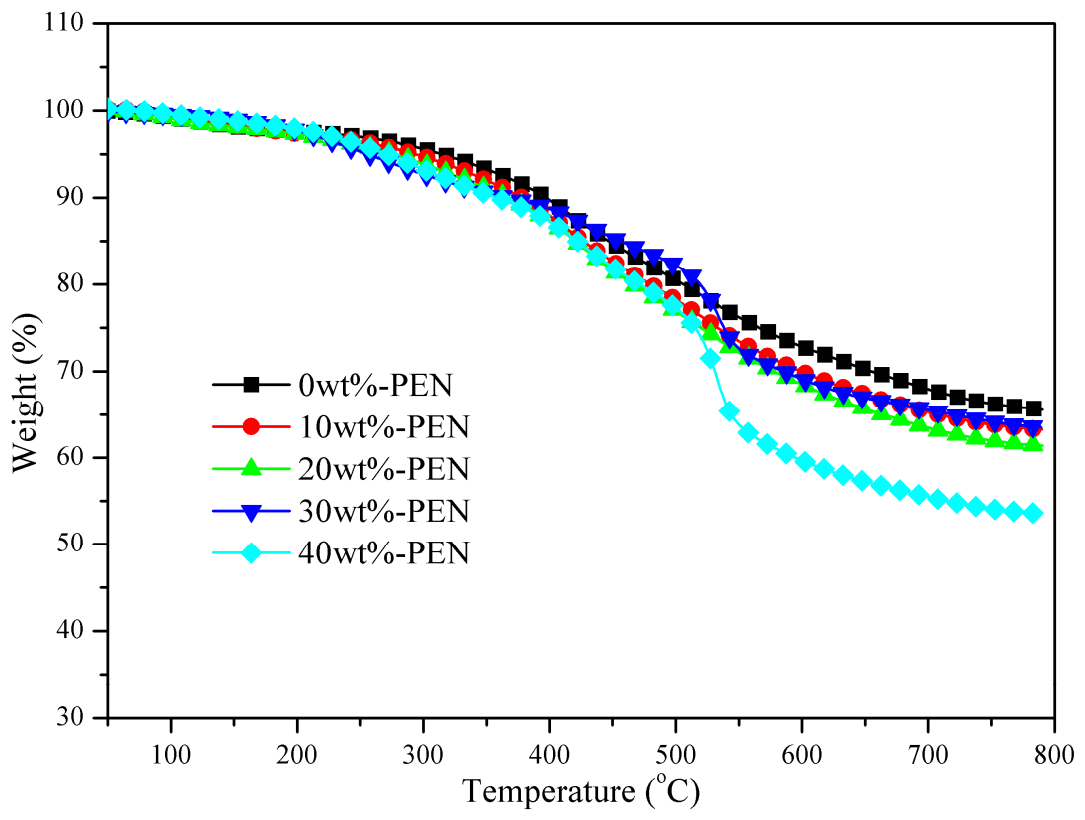

Figure 6. Thermal properties of the various composite laminates.

Table 2. Thermal properties of the various composite laminates.

\begin{tabular}{cccccc}
\hline & $\mathbf{0}$ wt $\%$ & $\mathbf{1 0} \mathbf{w t} \%$ & $\mathbf{2 0} \mathbf{w t} \%$ & $\mathbf{3 0} \mathbf{w t} \mathbf{\%}$ & $\mathbf{4 0} \mathbf{w t} \%$ \\
\hline$T_{5 \%}\left({ }^{\circ} \mathrm{C}\right)$ & 315.14 & 293.94 & 276.41 & 256.17 & 270.79 \\
$T_{10 \%}\left({ }^{\circ} \mathrm{C}\right)$ & 397.32 & 377.96 & 367.01 & 367.7 & 358.43 \\
Char yield $(\%)$ & 65.61 & 63.27 & 61.41 & 63.51 & 53.53 \\
\hline
\end{tabular}

\section{Conclusions}

In this work, the decorated GFs with PEN were designed and their reinforced matrix (BA-ph/PEN) composites were prepared at relative low process temperature $\left(200{ }^{\circ} \mathrm{C}\right)$. The curing behavior and dynamic rheological of BA-ph/PEN were studied, results indicated that the PEN existed in the matrix would hinder the curing reaction of the BA-ph. However, with introduction and increasing the content of PEN into the BA-ph matrix, the mechanical properties of the BA-ph/PEN/ $p$-GF composites were improved, which could be explained by the improvement of the matrix and the enhancement of the interfacial adhesion. Combined the results of DSC and DRA, semi-interpenetrating polymer networks may be formed during the copolymerization between PEN and BA-ph, which would improve the toughness of the matrix. Moreover, the PEN decorated on the GFs formed fish-scale on the surface of the GFs can significantly roughen the surface. The rough surface would significantly improve the interface compatibility through the entanglement of the molecular chains and the copolymerization of the active nitrile groups. The proposed hypothesis was confirmed with the investigation of the fracture surface and the thermal-mechanical properties. In this work, it's proposed that a convenient and efficient method to modify the brittleness and improve the interfacial interaction of the fiber-reinforced composites to obtain the composite laminates with improved properties. In our further study, the investigation of the formation of the interpenetrating polymer networks between the PEN and BA-ph polymers will be carried out in the successive works.

Author Contributions: Writing-Original Draft Preparation, D.R.; Conceptualization, M.X.; Methodology, L.C.; Investigation, Y.Y.; Data Curation, K.L.; Writing-Review and Editing, M.X.; Validation, X.L.; Funding Acquisition, X.L., M.X.

Funding: This research was funded by Natural Science Foundation of China, grant number is 51403029 and 51803020 . 
Acknowledgments: The authors wish to thank the financial support to this work provided by the Natural Science Foundation of China (No. 51403029, 51803020)

Conflicts of Interest: The authors declare no conflict of interest.

\section{References}

1. Li, Y.; Li, N.; Gao, J. Tooling design and microwave curing technologies for the manufacturing of fiber-reinforced polymer composites in aerospace applications. Int. J. Adv. Manuf. Technol. 2014, 70, 591-606. [CrossRef]

2. Liu, M.; Jia, K.; Liu, X. Effective thermal conductivity and thermal properties of phthalonitrile-terminated poly(arylene ether nitriles) composites with hybrid functionalized alumina. J. Appl. Polym. Sci. 2015, 132, doi. [CrossRef]

3. Xu, M.; Hu, J.; Zou, X.; Liu, M.; Dong, S.; Zou, Y.; Liu, X. Mechanical and thermal enhancements of benzoxazine-based GF composite laminated by in situ reaction with carboxyl functionalized CNTs. J. Appl. Polym. Sci. 2013, 129, 2629-2637. [CrossRef]

4. Ghosh, N.N.; Kiskan, B.; Yagci, Y. Polybenzoxazines-New high performance thermosetting resins: Synthesis and properties. Prog. Polym. Sci. 2007, 32, 1344-1391. [CrossRef]

5. Derradji, M.; Wang, J.; Liu, W.-B. High performance ceramic-based phthalonitrile micro and nanocomposites. Mater. Lett. 2016, 182, 380-385. [CrossRef]

6. Gupta, M.K.; Srivastava, R.K. Mechanical properties of hybrid fibers-reinforced polymer composite: A review. Polym.-Plast. Technol. Eng. 2016, 55, 626-642. [CrossRef]

7. Xiong, L.; Zhan, F.; Liang, H.; Chen, L.; Lan, D. Chemical grafting of nano- $\mathrm{TiO}_{2}$ onto carbon fiber via thiol-ene click chemistry and its effect on the interfacial and mechanical properties of carbon fiber/epoxy composites. J. Mater. Sci. 2018, 53, 2594-2603. [CrossRef]

8. Wu, W.; Wang, Q.; Ichenihi, A.; Shen, Y.; Li, W. The effects of hybridization on the flexural performances of carbon/glass interlayer and intralayer composites. Polymers 2018, 10, 549. [CrossRef]

9. Domiguez, D.D.; Keller, T.M. Low-melting phthalonitrile oligomers: Preparation, polymerization and polymer properties. High Perform. Polym. 2006, 18, 283-304. [CrossRef]

10. Dominguez, D.D.; Keller, T.M. Properties of phthalonitrile monomer blends and thermosetting phthalonitrile copolymers. Polymer 2007, 48, 91-97. [CrossRef]

11. Sumner, M.J.; Sankarapandian, M.; McGrath, J.E.; Riffle, J.S.; Sorathia, U. Flame retardant novolac-bisphthalonitrile structural thermosets. Polymer 2002, 43, 5069-5076. [CrossRef]

12. Xu, M.; Liu, M.; Dong, S.; Liu, X. Design of low temperature self-cured phthalonitrile-based polymers for advanced glass fiber composite laminates. J. Mater. Sci. 2013, 48, 8108-8116. [CrossRef]

13. Zeng, K.; Zhou, K.; Zhou, S.; Hong, H.; Zhou, H.; Wang, Y.; Miao, P.; Yang, G. Studies on self-promoted cure behaviors of hydroxy-containing phthalonitrile model compounds. Eur. Polym. J. 2009, 45, 1328-1335. [CrossRef]

14. Luo, Y.; Xu, M.; Pan, H.; Jia, K.; Liu, X. Effect of ortho-diallyl bisphenol a on the processability of phthalonitrile-based resin and their fiber-reinforced laminates. Polym. Eng. Sci. 2016, 56, 150-157. [CrossRef]

15. Xu, M.; Yang, X.; Zhao, R.; Liu, X. Copolymerizing behavior and processability of benzoxazine/epoxy systems and their applications for glass fiber composite laminates. J. Appl. Polym. Sci. 2013, 128, 1176-1184. [CrossRef]

16. Li, S.; Lin, Q.; Zhu, H.; Cui, C.; Hou, H.; Lv, T.; Li, Y. Investigations on mechanical characteristics of glass fiber reinforced epoxy composite modified with amino-terminated hyperbranched polymer. Fibers Polym. 2016, 17, 282-288. [CrossRef]

17. Lin, F.; Li, W.; Tang, Y.; Shao, H.; Su, C.; Jiang, J.; Chen, N. High-performance polyimide filaments and composites improved by $\mathrm{O}_{2}$ plasma treatment. Polymers 2018, 10, 695. [CrossRef]

18. Ren, D.; Lei, Y.; Pan, H.; Yan, L.; Xu, M.; Liu, X. Design of the phthalonitrile-based composite laminates by improving the interfacial compatibility and their enhanced properties. J. Appl. Polym. Sci. 2018, 135, 45811. [CrossRef]

19. Cech, V.; Janecek, P.; Lasota, T.; Bursa, J. A fiber-bundle pull-out test for surface-modified glass fibers in gf/polyester composite. Compos. Interfaces 2011, 18, 309-322. [CrossRef] 
20. Sabet, S.M.; Mahfuz, H.; Terentis, A.C.; Nezakat, M.; Hashemi, J. Effects of POSS functionalization of carbon nanotubes on microstructure and thermomechanical behavior of carbon nanotube/polymer nanocomposites. J. Mater. Sci. 2018, 53, 8963-8977. [CrossRef]

21. Jang, J.S.; Yang, H.J. The effect of surface treatment on the performance improvement of carbon fiber/polybenzoxazine composites. J. Mater. Sci. 2000, 35, 2297-2303. [CrossRef]

22. Yan, F.; Liu, L.; Li, M.; Zhang, M.; Xiao, L.; Ao, Y. Preparation of carbon nanotube/copper/carbon fiber hierarchical composites by electrophoretic deposition for enhanced thermal conductivity and interfacial properties. J. Mater. Sci. 2018, 53, 8108-8119. [CrossRef]

23. Jiang, B.; Zhu, A.; Zhang, C.; Li, Y. Interface enhancement between polytetrafluoroethylene and glass fibers modified with a titanate coupler. J. Appl. Polym. Sci. 2017, 134. [CrossRef]

24. Jing, M.; Che, J.; Xu, S.; Liu, Z.; Fu, Q. The effect of surface modification of glass fiber on the performance of poly(lactic acid) composites: Graphene oxide vs. silane coupling agents. Appl. Surf. Sci. 2018, 435, 1046-1056. [CrossRef]

25. Luo, G.; Li, W.; Liang, W.; Liu, G.; Ma, Y.; Niu, Y.; Li, G. Coupling effects of glass fiber treatment and matrix modification on the interfacial microstructures and the enhanced mechanical properties of glass fiber/polypropylene composites. Composites Part B 2017, 111, 190-199. [CrossRef]

26. Tang, H.; Yang, J.; Zhong, J.; Zhao, R.; Liu, X. Synthesis and dielectric properties of polyarylene ether nitriles with high thermal stability and high mechanical strength. Mater. Lett. 2011, 65, 2758-2761. [CrossRef]

27. Li, C.; Gao, N.; Liu, X. Compatibility, rheological, and thermal properties of the melt blends of PEN (HQ/PP) with PEN (HQ/RS). J. Appl. Polym. Sci. 2008, 108, 2934-2939. [CrossRef]

28. Wan, X.; Zhan, Y.; Zeng, G.; He, Y. Nitrile functionalized halloysite nanotubes/poly(arylene ether nitrile) nanocomposites: Interface control, characterization, and improved properties. Appl. Surf. Sci. 2017, 393, 1-10. [CrossRef]

29. Cao, G.P.; Chen, W.J.; Wei, J.J.; Li, W.T.; Liu, X.B. Synthesis and characterization of a novel bisphthalonitrile containing benzoxazine. Express Polym. Lett. 2007, 1, 512-518. [CrossRef]

30. Yang, X.; Li, K.; Xu, M.; Jia, K.; Liu, X. Designing a low-temperature curable phenolic/benzoxazine-functionalized phthalonitrile copolymers for high performance composite laminates. J. Polym. Res. 2017, 24, 195. [CrossRef]

31. Xu, M.Z.; Jia, K.; Liu, X.B. Effect of bisphenol-A on the structures and properties of phthalonitrile-based resin containing benzoxazine. Express Polym. Lett. 2015, 9, 567-581. [CrossRef]

32. Zhao, L.; Hu, X. Autocatalytic curing kinetics of thermosetting polymers: A new model based on temperature dependent reaction orders. Polymer 2010, 51, 3814-3820. [CrossRef]

33. Huang, Y.; Luo, Y.; Xu, M.; Lei, Y.; Liu, X. Studied on mechanical, thermal and dielectric properties of BPh/PEN-OH copolymer. Composites Part B 2016, 106, 294-299. [CrossRef]

34. Qu, Z.-T.; Duan, S.-Y.; Li, B.-B.; Sun, D.; Gu, Y.-L. PDMS/PVDF microporous membrane with semi-interpenetrating polymer networks for vacuum membrane distillation. J. Appl. Polym. Sci. 2018, 135, 45792. [CrossRef]

35. Cortes, L.Q.; Causse, N.; Dantras, E.; Lonjon, A.; Lacabanne, C. Morphology and dynamical mechanical properties of poly ether ketone ketone (PEKK) with meta phenyl links. J. Appl. Polym. Sci. 2016, 133. [CrossRef]

36. Coulson, M.; Cortes, L.Q.; Dantras, E.; Lonjon, A.; Lacabanne, C. Dynamic rheological behavior of poly(ether ketone ketone) from solid state to melt state. J. Appl. Polym. Sci. 2018, 135, 46456. [CrossRef]

37. James, J.; Thomas, G.V.; Pramoda, K.P.; Kalarikkal, N.; Thomas, S. Thermoplastic-elastomer composition based on an interpenetrating polymeric network of styrene butadiene rubber-poly(methyl methacrylate) as an efficient vibrational damper. New J. Chem. 2018, 42, 1939-1951. [CrossRef]

(C) 2018 by the authors. Licensee MDPI, Basel, Switzerland. This article is an open access article distributed under the terms and conditions of the Creative Commons Attribution (CC BY) license (http:/ / creativecommons.org/licenses/by/4.0/). 